The reactivity of aluminosilicate glasses in cements - effects of Ca content on dissolution characteristics and surface precipitation

Katrina C. Newlands and Donald E. Macphee *

Department of Chemistry, University of Aberdeen, Aberdeen, UK

* d.e.macphee@abdn.ac.uk 


\title{
The reactivity of aluminosilicate glasses in cements - effects of Ca content on dissolution characteristics and surface precipitation
}

\author{
The partial replacement of Portland cement (PC) by glassy aluminosilicates in \\ cementitious binders has been common practice for decades, offering concretes \\ with increased durability and long term strength compared with PC concretes. \\ However, these concretes typically display a much lower rate of strength \\ development and this limits practical levels of cement replacement. The factors \\ contributing to strength development in concrete are complex but amongst them \\ is the reactivity of the SCM, which has been associated with glass content, and \\ composition with respect to the ratio of network modifiers to network formers, \\ etc. This paper revisits the assessment of reactivity using a fundamental \\ dissolution approach and highlights a rapid migration of soluble constituents, \\ specifically $\mathrm{Ca}$, to the surface on contact with an activating solution. The \\ conditions which affect the composition of Ca-bearing precipitates and their role \\ in on-going hydration is discussed.
}

Keywords: aluminosilicate glass, early stage dissolution, blastfurnace slag, $\mathrm{Ca}$ reactivity

\section{Introduction}

Developing and maintaining a built infrastructure that is fit for purpose continues to be a major economic driver in the developed and now developing worlds. Consequently, the prominent role played by concrete in construction places increasing demands on the cement industry which must balance its levels of production with managing its impact on the environment; Portland cement production contributes around 5\% of global anthropogenic $\mathrm{CO}_{2}[1,2]$. Low lime content aluminosilicates, such as blastfurnace slag (BFS) and coal combustion fly ash (FA), have been used as supplementary cementitious materials (SCMs) by the cement industry for many years as a partial replacement for Portland cement (PC) [3]. Despite their long term contribution to durability and mechanical strength, their level of replacement is limited however, due 
to the slower rate of concrete strength development relative to PC concrete, as is shown in Figure 1 for the case of BFS [4]. As sustainability in construction continues to increase in importance, efficiencies in the use of materials are being vigorously pursued. This paper focuses on the reactivity of aluminosilicate glasses, with particular emphasis on their solubility-precipitation characteristics in different activators.

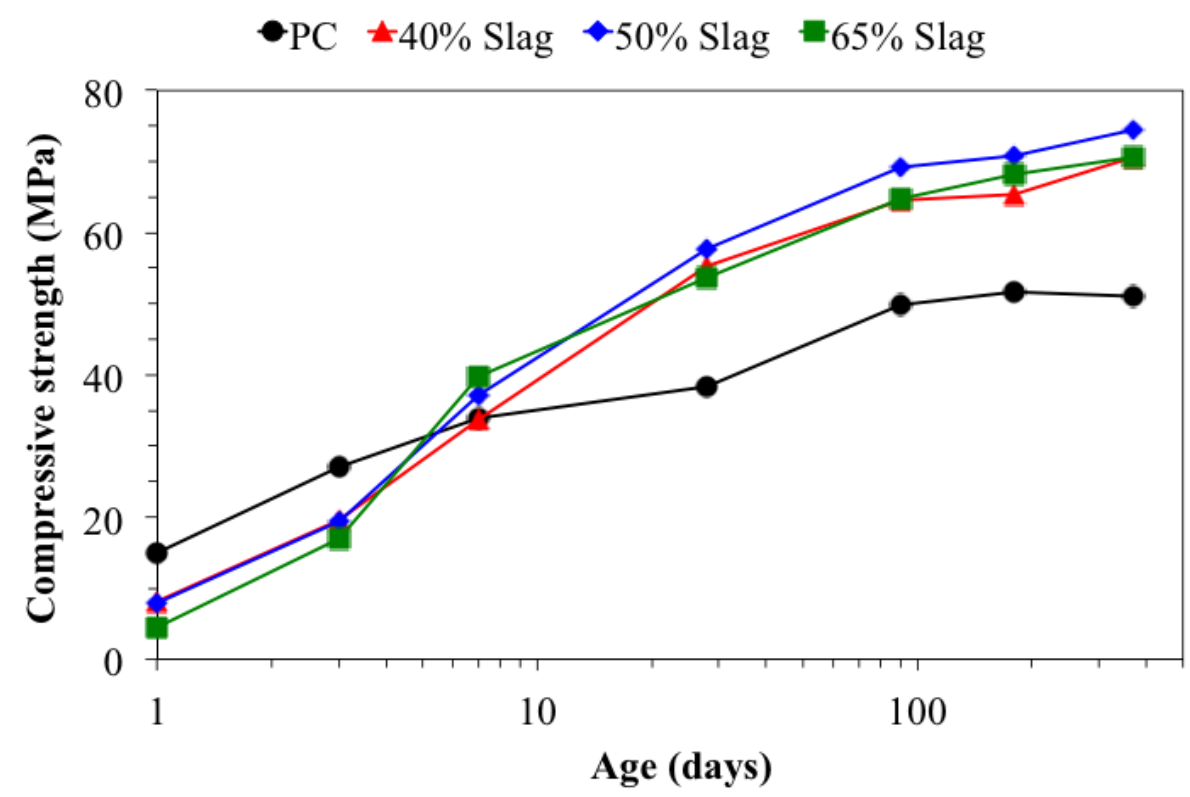

Figure 1: Strength evolution in BFS-OPC blends (redrawn from [4])

A number of empirical links between SCMs reactivity and composition have been identified; high glass content (> 95\%) and high hydraulic indices (ratios of glass network modifiers to network formers) [5]. These structure-performance correlations enable more detailed insights into the chemical characteristics of the glass and specifically the importance of the types of ion binding. 


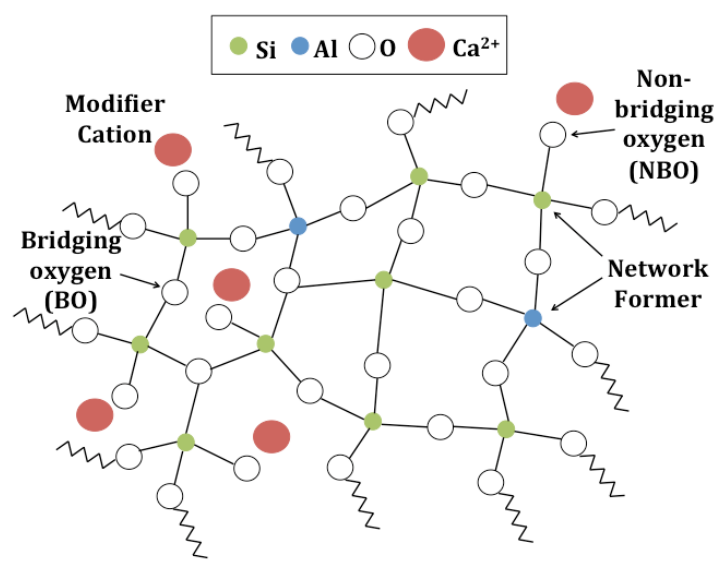

Figure 2: Schematic representation of a glassy (no long range order) aluminosilicate network

Figure 2 shows a generic, low crystallinity aluminosilicate network featuring 4coordinate $\mathrm{Al}$ and $\mathrm{Si}$ bonded via oxygen ion linkages. It is to be noted that whilst many oxide ions bridge between $\mathrm{Si}$ and $\mathrm{Si}$ or $\mathrm{Al}$, some do not and are termed non-bridging oxygens (NBOs). The NBO is a site which enables compensation of the charge imbalance arising from the incorporation of $\mathrm{Al}^{3+}$ in a network site requiring a $4+$ ion and it is here that network modifiers such as $\mathrm{Ca}$ are associated with the glass 'structure' in an ionic bond which, unlike the $\mathrm{Si}-\mathrm{O}$ or $\mathrm{Al}-\mathrm{O}$ covalent linkages, is vulnerable to attack by ionic (aqueous) solutions. It is from here that the well-known ion exchange reactions in glasses take place, whereby $\mathrm{Ca}$ becomes mobile as it is replaced by $\mathrm{H}^{+}$from solution (leached layer model). This process is the first in a series of consequential system changes, including variations in solution $\mathrm{pH}$ and aluminosilicate network hydrolysis reactions so it is evident that the glass composition is quite important. Clearly, the higher the concentration of NBOs, the higher the potential for ion mobility and the higher the reactivity on exposure to an aqueous solution. As an example, the higher $\mathrm{Al}_{2} \mathrm{O}_{3} / \mathrm{SiO}_{2}$ ratio in BFS, shown in Figure 3, means a higher level of charge balancing is required than for FA. The BFS network will have a higher NBO concentration and will therefore be more vulnerable to attack from aqueous solution 
than the lower $\mathrm{Al}_{2} \mathrm{O}_{3} / \mathrm{SiO}_{2}$ ratio, lower $\mathrm{Ca}$ content $\mathrm{FA}$ glass; however, FA

solubility/reactivity may be further influenced by its higher crystalline content. The BFS is therefore predicted to be more reactive than FA which is well-documented [6-8].

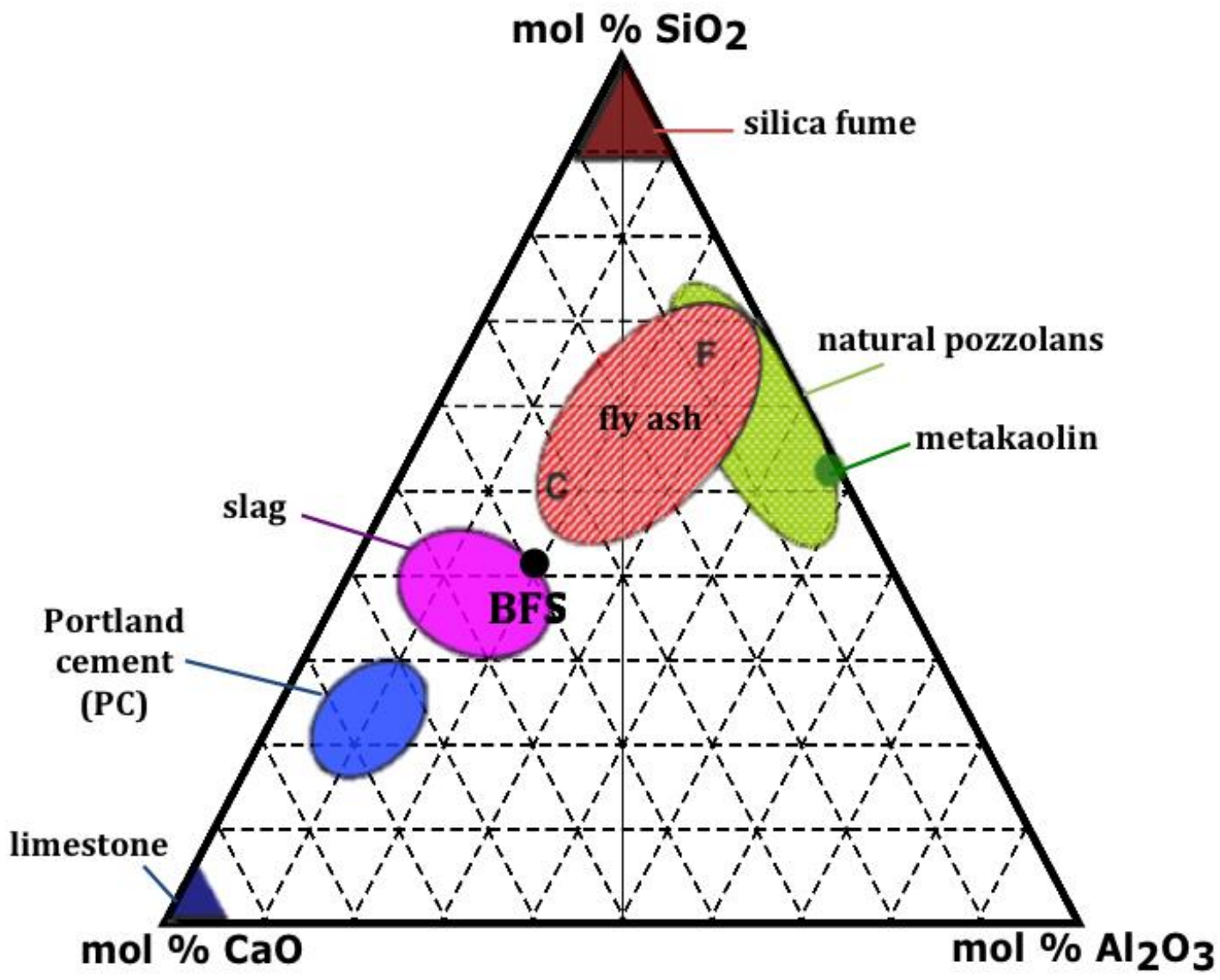

Figure 3. $\mathrm{CaO}-\mathrm{SiO}_{2}-\mathrm{Al}_{2} \mathrm{O}_{3}$ ternary phase diagram (mol\%) showing the compositions of typical SCMs. The composition of the synthesised BFS glass is indicated.

Despite this conceptual approach to modelling aluminosilicate reactivity, there are still challenges in predictive reactivity modelling. SCMs provide a 'filler' effect which enhances precipitation of PC hydration products on SCM surfaces $[9,10]$. SCM hydration products are similar in composition to that of PC hydration products which makes direct differentiation of reaction rates difficult. These factors complicate the definition of SCM reaction kinetics. The approach taken in the present study utilises aqueous solutions to activate a synthetic BFS-like to simplify the system and to avoid 
the complicating influence of $\mathrm{PC}$ reactivity. A selection of activating solutions allows variations in $\mathrm{pH}$ and ion composition to monitor the effects on rates of hydrolysis of the aluminosilicate network and to monitor dissolution profiles as well as surface precipitation characteristics which influences mass transport through the changing surface.

\section{Materials and methods}

Synthetic BFS glass of composition $41.98 \pm 1.03 \mathrm{SiO}_{2}, 17.37 \pm 1.75 \mathrm{Al}_{2} \mathrm{O}_{3}$ and $40.66 \pm 0.34 \mathrm{CaO}$ mol\% (Figure 3), was prepared by firing mixtures of $\mathrm{CaCO}_{3}, \mathrm{Al}_{2} \mathrm{O}_{3}$ and $\mathrm{SiO}_{2}$ in appropriate molar proportions at $1550^{\circ} \mathrm{C}$ and quenching the melt on a brass plate. The glass was ground to particles sizes of approx. $100 \mu \mathrm{m}$ as defined firstly by sieving and then by laser scattering (Beckman Coulter LS 13320 Laser Diffraction Particle Size Analyser). Table 1 summarises further characteristics including surface area determination by nitrogen adsorption (Tristar 3000) and glass transition temperature, $T_{g}$, obtained by differential scanning calorimetry (Netzsch Pegasus DSC 404C).

XRD patterns (Panalytical X'Pert Pro diffractomer equipped with a Cu Ka1 $1.54 \AA$ Xray source) were recorded in the range $10^{\circ}<2 \theta<50^{\circ}$ with a $0.0263^{\circ}$ step size to confirm the amorphous nature of the glass.

NBO/T were calculated using equation (1)[11-13]

$$
\frac{N B O}{T}=\frac{2[\mathrm{Ca}]-[\mathrm{Al}]}{[\mathrm{Si}]+[\mathrm{Al}]}
$$

This calculation provides an approximation only; an accurate calculation would require the exact coordination of $\mathrm{Al}$ in the glass to be known [14]. 
The number of Al-O-Si linkages per Si tetrahedron are taken as 4 times the bulk $\mathrm{Al} / \mathrm{Si}$ atom ratio, assuming a random distribution of alumina tetrahedra, a low $\mathrm{Al} / \mathrm{Si}$ ratio and no Al-O-Al linkages as they are unfavourable [15]. A higher number of Al-O-Si linkages over $\mathrm{Si}-\mathrm{O}-\mathrm{Si}$, will result in higher dissolution rates due to the more favourable hydrolysis of Al-O-Si bonds which will preferentially release $\mathrm{Al}$ into solution leaving a Si-rich surface layer $[3,16]$.

Table 1: BFS glass characteristics

\begin{tabular}{|l|c|}
\hline Size $(\boldsymbol{\mu m})$ & 110.7 \\
\hline SA $\left(\mathbf{m}^{\mathbf{2}} \mathbf{. g}^{-\mathbf{1}}\right)$ & 0.042 \\
\hline $\mathbf{N B O} / \mathbf{T}$ & 0.61 \\
\hline $\mathbf{A l - O - S i}$ & 3.30 \\
\hline Si-O-Si & 0.69 \\
\hline $\mathbf{T}_{\mathbf{g}}(\mathbf{K})$ & 1160 \\
\hline
\end{tabular}

The synthetic BFS glass was cleaned in acetone and dried at $60^{\circ} \mathrm{C}$ before $0.1 \mathrm{~g}$ was introduced to a reactor with an activator solution of either deionised $\mathrm{H}_{2} \mathrm{O}$ (resistivity > $18 \mathrm{M} \Omega \mathrm{cm}$ ), $1 \mathrm{mM}$ and $0.1 \mathrm{M} \mathrm{NaOH}$ or $\mathrm{KOH}$ (Fisher Chemicals; analytical grade) or $\mathrm{Ca}(\mathrm{OH})_{2}(0.5-8 \mathrm{mM}$; prepared from solutions of $\mathrm{CaO}$, derived from the calcination of $\mathrm{CaCO}_{3}$, (Sigma Aldrich) at $1000^{\circ} \mathrm{C}$ ) to provide a liquid to solid ratio of 10,000 , considered high enough to prevent precipitation. The solid was retained in a plastic mesh basket suspended into the volume of the reactor above a magnetic stirrer rotating at $700 \mathrm{rpm}$. The internal volume was protected against intrusion of air by continuous purging with a slow stream of nitrogen. An integrated sampling system enabled recovery of the liquid periodically from 5 minutes to 3 hours after initial mixing. Solutions were filtered through a $0.2 \mu \mathrm{m}$ porosity filter and acidified with 
$1 \% \mathrm{HNO}_{3}$. An equivalent volume of liquid activator was replaced after each sample was withdrawn.

For the glasses exposed to Ca solutions, released $\mathrm{Ca}$ was determined by comparing time dependence of $\mathrm{Ca}$ concentrations with solutions where no $\mathrm{Ca}$ was added. In the latter case a $1 \mathrm{mM} \mathrm{NaOH}$ solution was used to maintain comparable solution $\mathrm{pH}$ values. For Ca complexation studies, 0.05 M ethylenediaminetetraacetic acid (EDTA, Fluka Chemika) solution was used with $\mathrm{pH}$ adjusted to $\mathrm{pH} 8$ with dropwise addition of $10 \mathrm{M}$ $\mathrm{NaOH}$. No acidification step was used for EDTA solutions prior to analyses. Solution analyses were undertaken with a Microwave Plasma - Atomic Emission Spectrometer (MP-AES) using matrix matched standard solutions.

The solid sample was removed at the end of each experiment in order to maintain a constant SA/V, washed with water and the reaction stopped with isopropanol. Surface analyses were undertaken by X-ray Photoemission Spectroscopy (XPS, Kratos AXIS Ultra DLD) and Time of Flight-Secondary Ion Mass Spectrometry (TOF-SIMS, IonTof TOF.SIMS ${ }^{5}$ ). XPS measurements were performed using Monochromatic Al Ka X-rays and data extracted from the spectra via peak fitting using CasaXPS software and a Kratos Library. Shirley background was assumed in all cases and spectra were corrected for charging effects using the adventitious $\mathrm{C} 1 \mathrm{~s}$ peak at $284.8 \mathrm{eV}$. Surface spectra were recorded using TOF-SIMS with a $\mathrm{Cs}^{+}$sputter gun and a flood gun to reduce surface charge build up. Due to the lack of an appropriate standard, elemental counts are reported as a percentage of the total secondary ions emitted. Some additional analyses were undertaken by Scanning Electron Microscopy (SEM), Atomic Force Microscopy (AFM) and Laser Ablation-Inductively Coupled Plasma-Mass Spectrometry (LA-ICPMS). 


\section{Results and Discussion}

Solution analyses Results for the system BFS- $\mathrm{H}_{2} \mathrm{O}$ are shown in Figure 4. The variation in the normalised analytical concentrations of a specific ion $\left(\mathrm{Q}_{\mathrm{norm}}, \mathrm{mol} / \mathrm{cm}^{2}\right)$ in relation to specific surface area (SSA, $\left.\mathrm{cm}^{2} / \mathrm{g}\right)$, sample mass $(\mathrm{m}, \mathrm{g})$, volume of solution used $\left(\mathrm{V}_{\text {soln }}, \mathrm{L}\right)$ and atomic fraction of the element in the glass $\left(\mathrm{x}_{\mathrm{i}}\right)$ [15], given by equation (2),

$$
\mathrm{Q}_{\text {norm }}=\frac{\mathrm{C}_{\mathrm{i}} \cdot \mathrm{V}}{\mathrm{SSA} \cdot \mathrm{m} \cdot \mathrm{x}_{\mathrm{i}}}
$$

is presented in Figure 4. The $\mathrm{Al}$ and Si profiles are characterised by a gradual increase in aqueous concentration with time, achieving a constant gradient after about 2000s, the $\mathrm{Al}$ concentration being lower than that of Si. In contrast, the Ca profile shows an apparent peak in the first 1000s. In fact, it is not clear where the maximum is as the highest concentration is recorded at the first sampling (300s); the initial flux of Ca from the glass appears to be relatively sudden. After this time, there is a drop in aqueous $\mathrm{Ca}$ before a gradual increase is observed. At this point, $\mathrm{Ca}, \mathrm{Al}$ and $\mathrm{Si}$ species are monotonously increasing in concentration in what is assumed to be a steady state dissolution regime. 


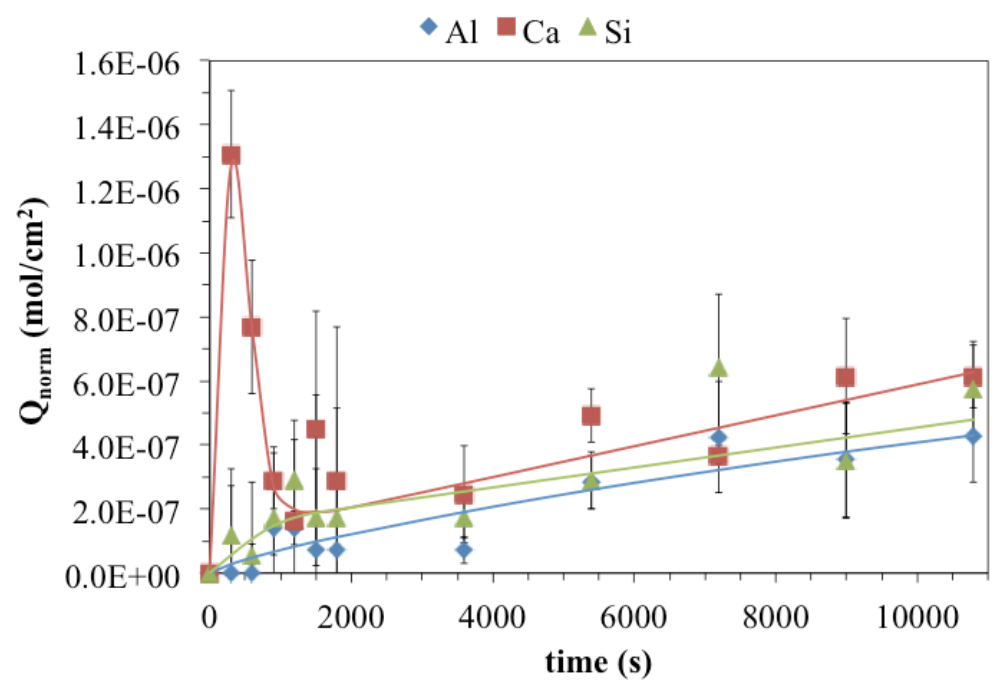

Figure 4. Release of $\mathrm{Al}, \mathrm{Ca}$ and $\mathrm{Si}\left(\mathrm{mol} / \mathrm{cm}^{2}\right.$ glass) vs. time (min) for BFS exposed to $\mathrm{H}_{2} \mathrm{O}$ at $1 / \mathrm{s} 10,000$

With only a few exceptions, this short-term feature has not been typically reported in glass dissolution studies but it was evident in all BFS-activator solution systems studied here.

For the purpose of discussion and to facilitate comparison between activator solutions, the release rates of $\mathrm{Al}, \mathrm{Ca}$ and $\mathrm{Si}\left(r\right.$ in $\left.\mathrm{mol} / \mathrm{cm}^{2} / \mathrm{s}\right)$ normalised to the atomic fraction of the element in the glass were calculated using equation (3) and plotted over time (min) in Figure 5.

$$
r=\frac{Q_{n o r m}}{t}
$$

All dissolution rate profiles show an initial release of all elements followed by a slower rate of release and then steady-state behaviour. The initial release of $\mathrm{Al}$ and $\mathrm{Si}$ can be attributed to the hydrolysis reactions occurring at the surface of the glass. Ca release is considered to be a consequence of matrix dissolution but also of ion-exchange with 
protons ahead of the matrix dissolution front as discussed above. $\mathrm{In}_{2} \mathrm{O}$ (Figure 5(a)), this is significantly faster than for the $\mathrm{Al}$ and $\mathrm{Si}$ release. The increased dissolution rate of the aluminosilicate in $\mathrm{NaOH}$ is due to the increased rate of hydrolysis in alkaline solutions and is affected also by the different coordination environments at the surface from that in the bulk [17].

The lower rates of dissolution in $\mathrm{KOH}$ relative to $\mathrm{NaOH}$ activator solutions (Figure 5 (b and c)) may be attributed to the charge density difference between $\mathrm{Na}^{+}$and $\mathrm{K}^{+}$[18] which influences the stability of the hydration sheath on the hydrated ion. This has been shown to influence the coagulation behaviour of silica sols, the surface reactions of which can be considered similar to that occurring at the aluminosilicate surface. The larger $\mathrm{K}^{+}$ion more readily relinquishes water to participate in direct interaction and charge compensation with the silicate anion, blocking further hydrolysis [19] and reducing dissolution rate. Also, the smaller $\mathrm{Na}^{+}$ion will interact more strongly with surrounding anions and thus be more active resulting in a higher extent of dissolution in $\mathrm{NaOH}$ solutions [20]. 

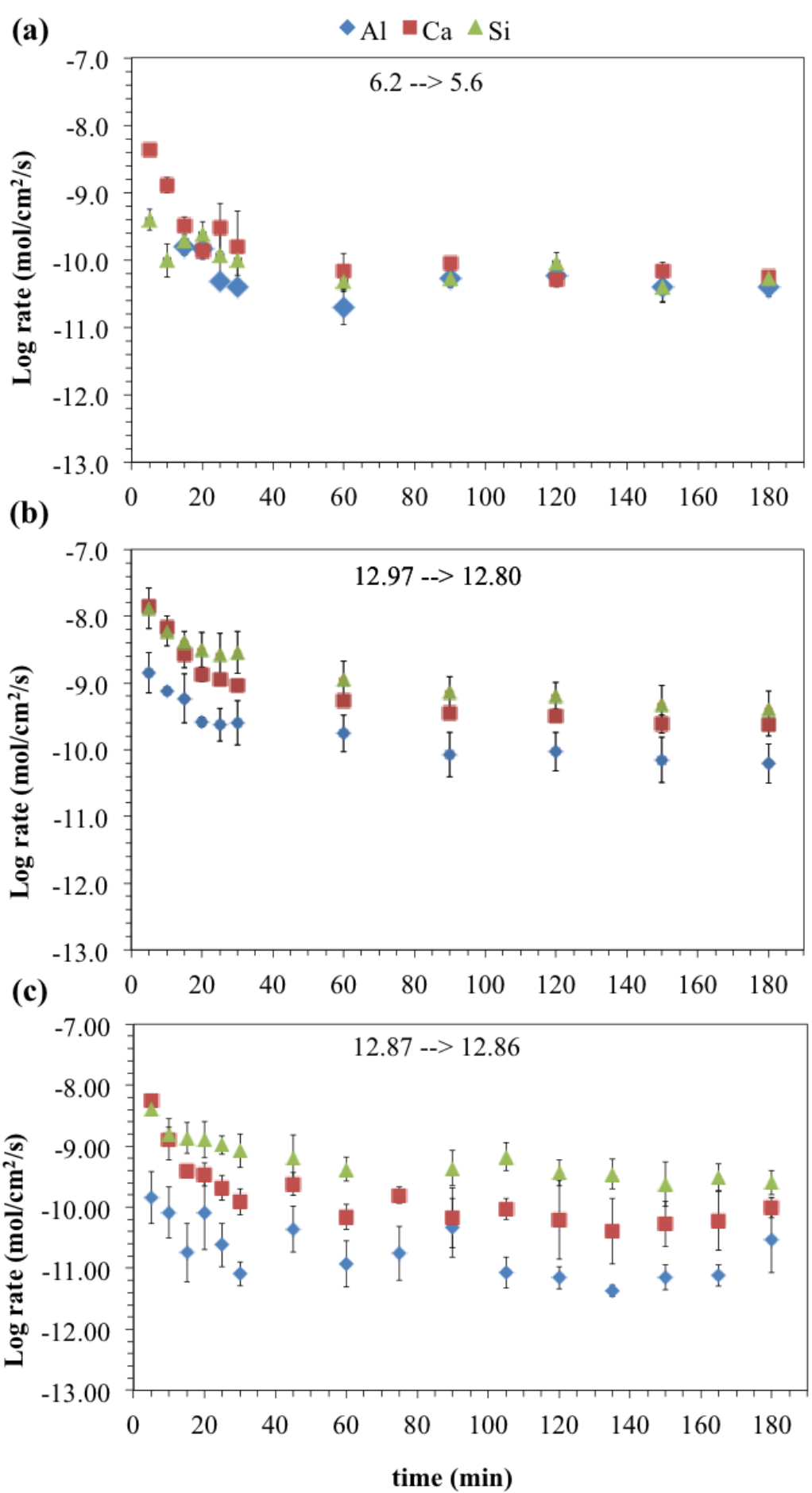

Figure 5. Log of the normalised elemental fluxes $\left(\mathrm{mol} / \mathrm{cm}^{2} / \mathrm{s}\right.$ ) over time (min) for BFS in (a) $\mathrm{H}_{2} \mathrm{O}$, (b) $0.1 \mathrm{M} \mathrm{NaOH}$, and (c) $0.1 \mathrm{M} \mathrm{KOH}$

It can be noted that high release rates were also observed after successive hydrolysis experiments [21] which shows that the effect is not the result of surface fines created 
during the grinding stage. In all cases, the Ca concentration subsequently drops to a minimum before a steady state profile similar to that illustrated by $\mathrm{Al}$ and $\mathrm{Si}$ is shown. At this stage, Ca has been reabsorbed onto the surface either as a new precipitate or as an adsorbed aqueous ion.

Noticeable in solution analysis was a $\mathrm{pH}$ decrease at the end of the $3 \mathrm{~h}$ experiment (Figure 5). A small possibility of $\mathrm{CO}_{2}$ interaction with the solution arises during $\mathrm{pH}$ measurement, only measurable by opening the reactor, but other studies also report $\mathrm{pH}$ change or the need to adjust $\mathrm{pH}$ values during the experiment $[15,22,23]$. Chave et al. [24] took rigorous precautions to lower the risk of $\mathrm{CO}_{2}$ contamination but still observed a $\mathrm{pH}$ drop of $0.2-0.6$ units between each sampling operation and proposed the following mechanism based on an acid-base equilibrium between $\mathrm{Ca}(\mathrm{OH})_{2}$ in solution and the acid sites on the surface.

$$
\equiv \mathrm{Si}-\mathrm{OH}+\mathrm{Ca}^{2+}+\mathrm{HO}-\mathrm{Si} \equiv \rightarrow \equiv \mathrm{Si}-\mathrm{O}-\mathrm{Ca}-\mathrm{O}-\mathrm{Si} \equiv+2 \mathrm{H}^{+}
$$

This builds upon the ion exchange mechanism discussed above in which $\mathrm{H}^{+}$replaces $\mathrm{Ca}^{2+}$ at NBOs and $\mathrm{Ca}$ is released to the solution. The uptake of $\mathrm{H}^{+}$creates an excess in solution of $\mathrm{OH}^{-}$which hydrolyses the Al-O-Si/Si-O-Si network [25], producing exposed negative surface charges. These attract the positive $\mathrm{Ca}^{2+}$ from solution, encouraging reabsorption of $\mathrm{Ca}$ at the surface as observed. Further, the dissolving matrix, releasing $\mathrm{Al}$ and $\mathrm{Si}$ to the solution, also releases $\mathrm{H}^{+}$, previously associated with NBOs. Those $\mathrm{H}^{+}$ contribute to the $\mathrm{H}^{+} / \mathrm{OH}^{-}$balance in solution and could account for the $\mathrm{pH}$ reduction if the $\mathrm{OH}^{-}$is consumed in hydrolysis.

A further chemical consequence of $\mathrm{pH}$ is its impact on Ca reactivity [16]. Just as increasing $\mathrm{pH}$ increases hydrolysis and rates of dissolution of the aluminosilicate network, hydrolytic dissociation of hydrated Ca ions leads to the progressive loss of $\mathrm{H}^{+}$ from water molecules in the hydration layer, the first step being the formation of 
${ }^{+} \mathrm{CaOH}(\mathrm{aq})$. The formation constant for this species $\left(\mathrm{K}_{\mathrm{h}}=10^{1.36}[26]\right)$ reveals that ${ }^{+} \mathrm{CaOH}(\mathrm{aq})$ begins to become quantitatively significant at $\mathrm{pH}>11$, which coincidentally is in the region of the minimum $\mathrm{pH}$ for the stabilisation of $\mathrm{C}-\mathrm{S}-\mathrm{H}$ gel and may reflect a condition for Ca reactivity. This would be consistent with the interaction of $\mathrm{Ca}(\mathrm{aq})$ with aluminosilicate zeolites, which at neutral $\mathrm{pH}$ is passive, with $\mathrm{Ca}^{2+}(\mathrm{aq})$ uptake into the zeolite by ion exchange for $\mathrm{Na}^{+}$for example. At cement-relevant $\mathrm{pH}$, aluminosilicate zeolites can undergo pozzolanic reaction with $\mathrm{Ca}$ to produce $\mathrm{C}-(\mathrm{A})-\mathrm{S}-\mathrm{H}$ gel. This has significance for the role played by $\mathrm{Ca}$ as the $\mathrm{pH}$ changes at the aluminate surface due to ion exchange and other surface reactions as discussed above.

Solids analyses TOF-SIMS and XPS were used to examine the outermost layers of the glass surface and showed complementary trends with the solution data. Figures 6 and 7 show ion ratios derived from both techniques as a function of analyses time for $\mathrm{H}_{2} \mathrm{O}$ and $0.1 \mathrm{M} \mathrm{NaOH}$ respectively. Data are from XPS (a) and ToF-SIMS (b) analysis. Dashed lines across the graph represent the relevant ratios in the pristine glass

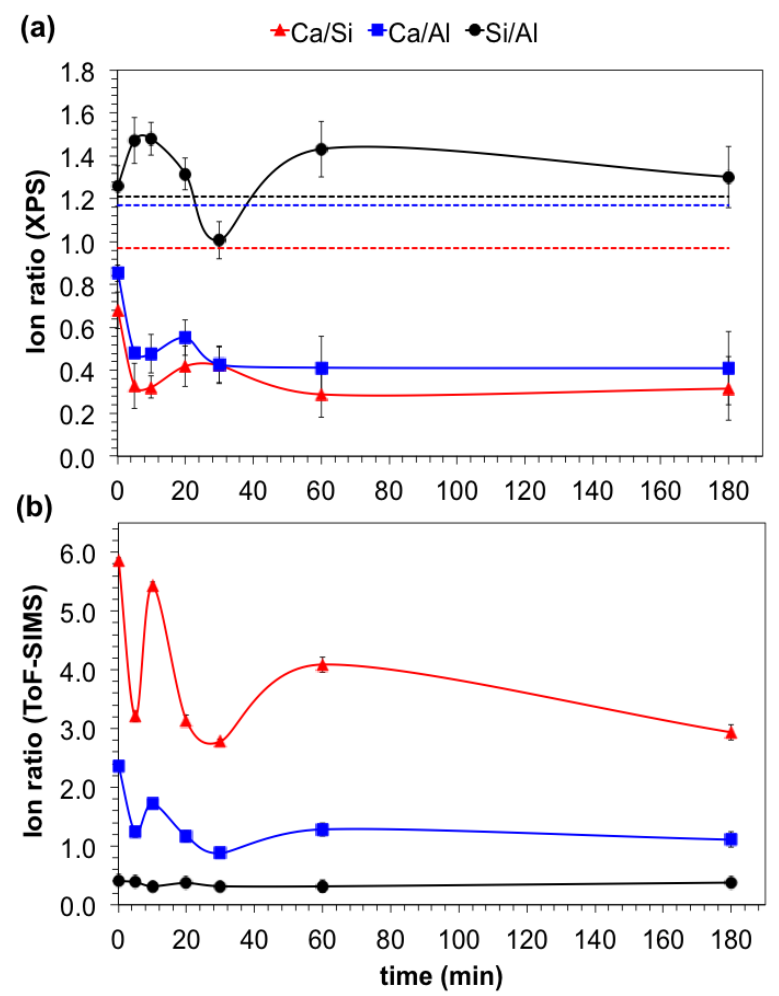


Figure 6. Ion ratio plots for synthetic BFS glass exposed to $\mathrm{H}_{2} \mathrm{O}$.
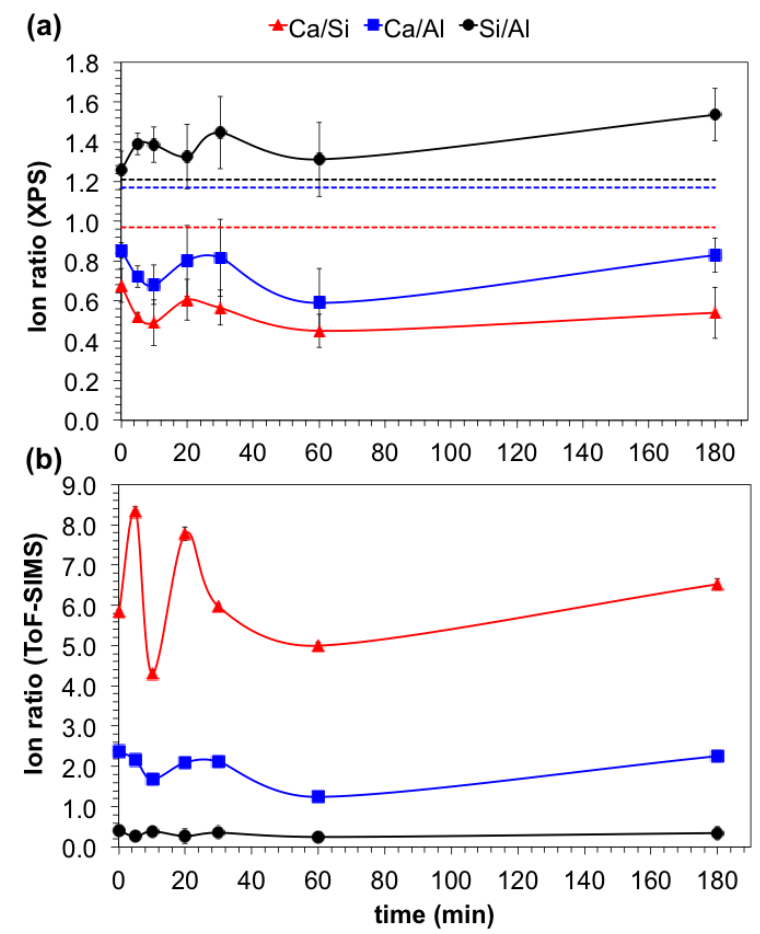

Figure 7. Ion ratio plots for synthetic BFS glass exposed to $0.1 \mathrm{M} \mathrm{NaOH}$

XPS and TOF-SIMS analyses penetrate the sample to different depths; XPS to between 6 and $12 \mathrm{~nm}[27,28]$ and TOF-SIMS to around $1.5 \mathrm{~nm} \mathrm{[28]} \mathrm{and} \mathrm{analytical} \mathrm{data} \mathrm{reflect}$ average ion ratios over the depth of penetration for the respective techniques. This penetration depth differentiation offers important insights into what is happening at the near surface of the glass; for the $\mathrm{H}_{2} \mathrm{O}$ data set, ToF-SIMS data, although semiquantitative, indicate that there is Ca enrichment in the first $1.5 \mathrm{~nm}$ of the BFS glass surface whilst XPS indicates Si enrichment in the first 6-12 nm. This apparent contradiction can best be illustrated using the schematic in Figure 8 which shows $\mathrm{Ca} / \mathrm{Si}$ ratio analyses based on two sampling times ( 5 and 180 minutes). Taking the 5 minute data for either activator, the surface enrichment of $\mathrm{Ca}$ (relative to the pristine (bulk) glass) is indicated by the average ToF-SIMS-derived ion ratio corresponding to a depth 
of $1.5 \mathrm{~nm}$. The corresponding ion ratio from XPS is somewhat lower (depleted with respect to the pristine glass) but this now extends to a greater depth, e.g. $10 \mathrm{~nm}$. Satisfying these values as averages across the respective length scales enables a composition profile with depth to be postulated as shown.

The relative positions of the pristine glass-modified layer boundary are estimated from the application of an equivalent layer thickness model $[29,30]$ to the solution data. The modified layer defines a zone affected by 'leaching', in practice, where network modifiers have been mobilised via ion exchange. However, the highly alkaline $\mathrm{NaOH}$ solution is aggressive towards the network which supports the NBO exchange sites and consequently the rate of dissolution is greater than the rate of ion exchange and diffusion.

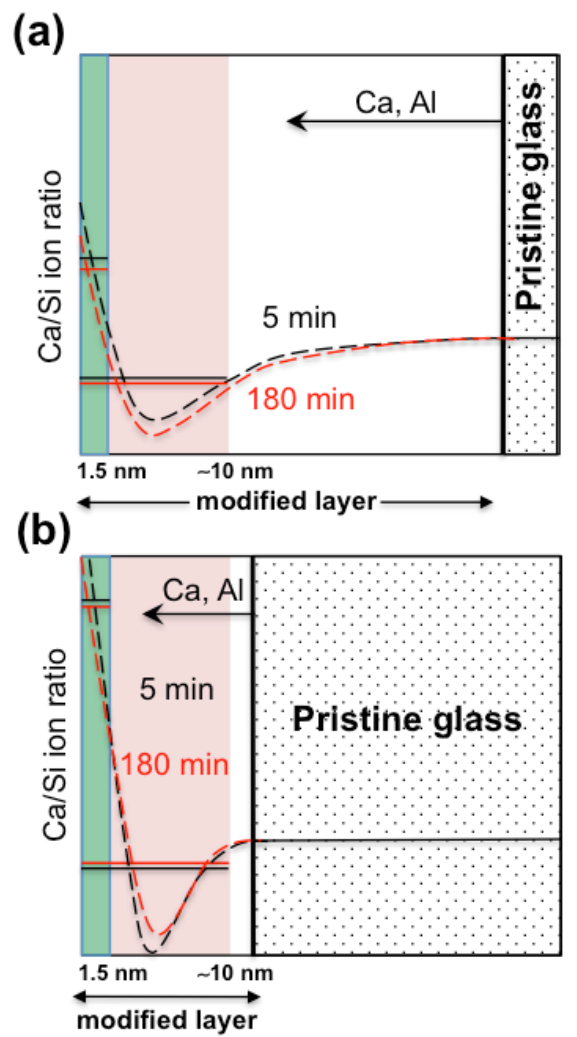

Figure 8. Potential compositional profile in (a) $\mathrm{H}_{2} \mathrm{O}$-activated and (b) $0.1 \mathrm{M} \mathrm{NaOH}-$ activated BFS glass, based on ToF-SIMS and XPS data 
Of significance in the ToF-SIMS data is the surface enrichment of $\mathrm{Ca}$ in the pristine glass (Figure 6-7 (b)) suggesting some level of activation prior to contact with the solution. A previous auger spectroscopy investigation by Hench et al [31] on soda lime silica glass showed similar transport effects following only a few minutes of exposure to air. This together with the present ToF-SIMS study offers some explanation for the initial release of $\mathrm{Ca}$, observed in the solution data. Exposure of the glass to laboratory air at normal temperature and humidity is likely to have activated the surface condensation of water and penetration of $\mathrm{H}^{+}$to $\mathrm{NBO}$ sites, leading to the release and transport of $\mathrm{Ca}$ which accumulates at the near surface. Exposure to the activator solution rapidly dissolves the accumulated $\mathrm{Ca}$ which is subsequently reabsorbed into or onto surface reaction products.

The effect of Ca on dissolution rate Ca reabsorption by the glass surface, as indicated by solution data, is evident in both the $\mathrm{pH}$ neutral and alkaline systems. However, this does not imply the same mechanism is active. Indeed, as discussed above, the surface characteristics of the aluminosilicate glass network as well as the reactivity of aqueous $\mathrm{Ca}$ are strongly influenced by $\mathrm{pH}[16,30]$. At neutral $\mathrm{pH}$, hydrated $\mathrm{Ca}$ ions are likely to be adsorbed on a negatively charged aluminosilicate surface whereas at higher $\mathrm{pH}$, there will be a tendency towards chemical reactivity and the formation of covalently bonded calcium silicate or aluminosilicate phases (C-S-H/C(A)-S-H). It is interesting however that the high w/s ratios used has given solution compositions which are undersaturated with respect to known cement-relevant phases (with the possible exception of gibbsite $\left(\mathrm{Al}(\mathrm{OH})_{3}\right)$ suggests that either the solubility limiting phase is not yet characterised or that it is not in equilibrium with the bulk 
solution; composition gradients may be enhanced by diffusion limitations in porous surface layers [32].

In any case, the effect of any Ca-bearing phases on dissolution behaviour is most likely reflected in the 'steady state' dissolution rates of the network former ions, specifically Si indicated by the long term (flat) portion of the rate data in Figure 9(a) to show the effect of $\mathrm{Ca}$ additions of 0.5 to $8 \mathrm{mM}$ on the dissolution rates of BFS glass in water. Although there is some scatter in the data, a decrease in the steady state rate of $\mathrm{Si}$ release from the glass is evident. This passivating effect has previously been observed for glasses already containing $\mathrm{Ca}$, such as the BFS glass and has been associated with the formation of hydration products (hydrated calcium silicates) covering the surface [33], or being integrated in the hydrated layer [24]. 

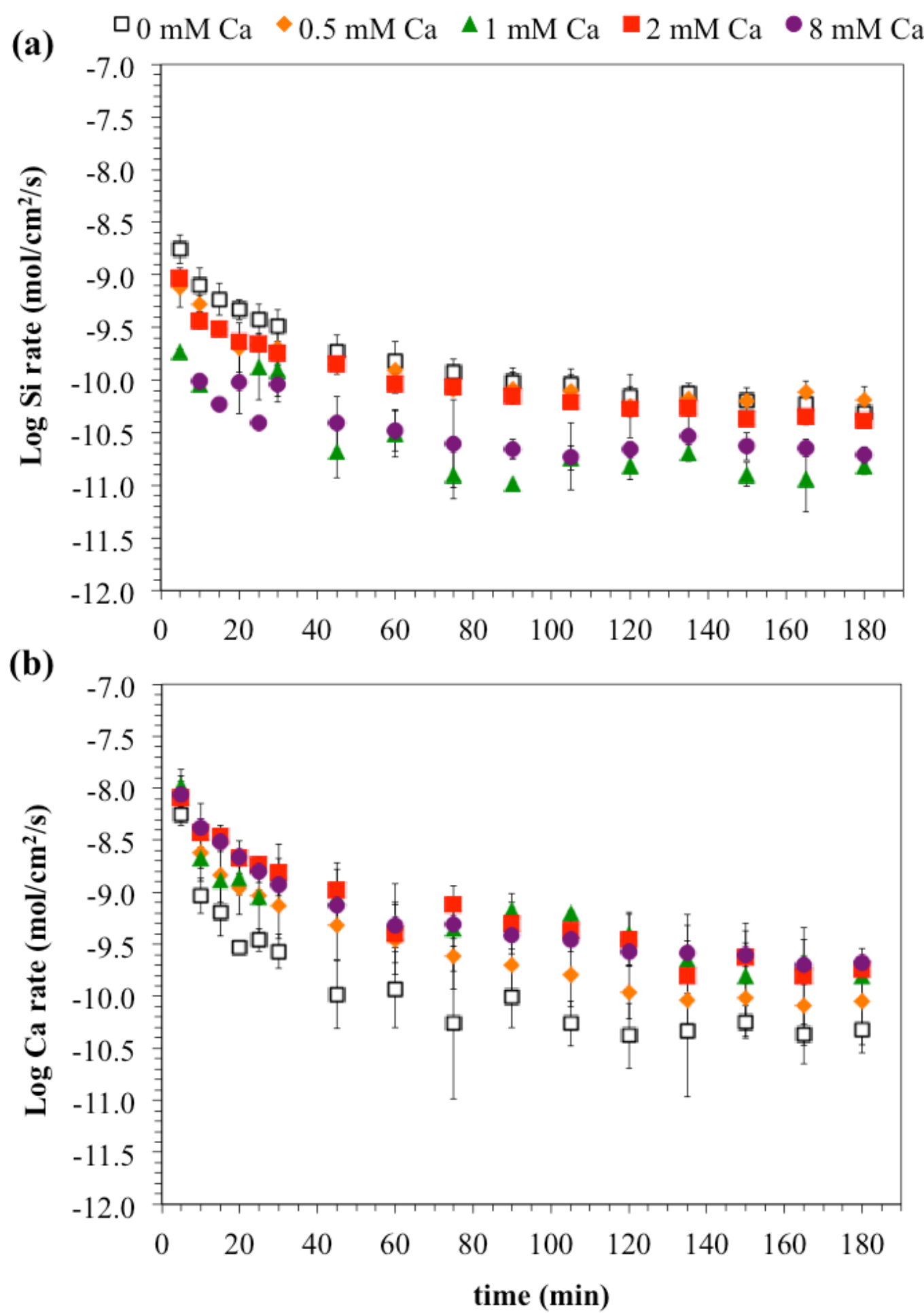

Figure 9: Effect of $\mathrm{Ca}$ addition to the aqueous solution on; (a) $\mathrm{Si}$ and (b) Ca fluxes during dissolution in solutions with $0,0.5,1,2,8 \mathrm{mM}$ Ca additions

It can also be noted that addition of $\mathrm{Ca}$ increases the rate of $\mathrm{Ca}$ released from the solid (Figure 9(b)). This observation most likely reflects the solubility characteristics of the 
phase responsible for the re-absorption of $\mathrm{Ca}$ from solution rather than those of the underlying glass. In the case that this were a C-S-H-like phase, increased Ca content would contribute a higher $\mathrm{Ca}$ (and a lower $\mathrm{Si}$ ) release rate to solution which would be consistent with the observed behaviour.

The passivating effect with respect to glass dissolution of additional $\mathrm{Ca}$ is reversed by the aqueous complexation of $\mathrm{Ca}$ in EDTA (Figure 10) which shows no reabsorption of $\mathrm{Ca}$ and an enhanced $\mathrm{Si}$ concentration in solution. Taken together, the data of Figures 9 and 10 confirm the importance of $\mathrm{Ca}$ in controlling glass dissolution rate and some similarities in effect can be observed on reactivity of BFS in cementitious systems, where the degree of slag hydration in the first 28 days is enhanced by the presence of $\mathrm{Ca}$ complexing agents [34].

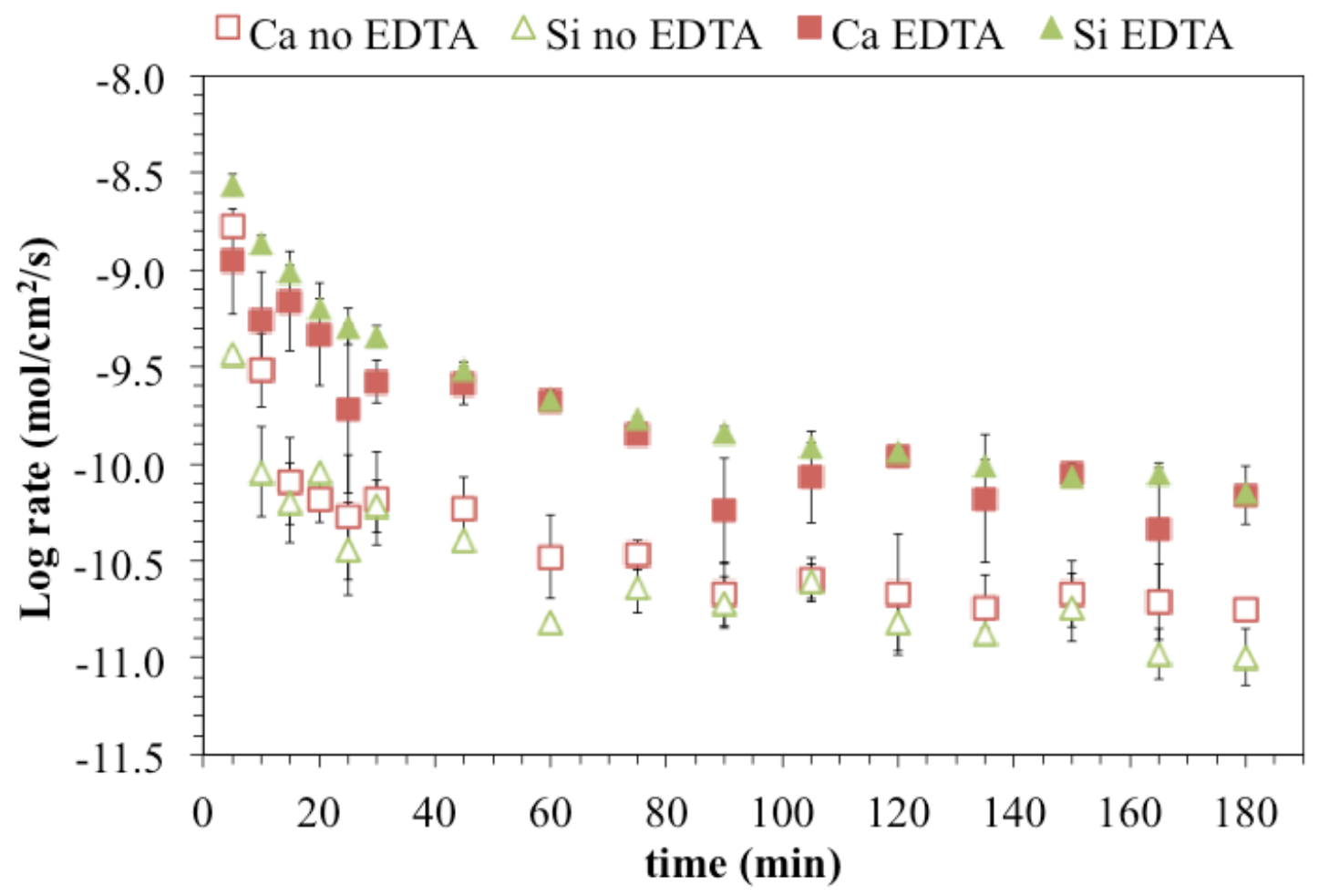

Figure 10. Influence of a Ca-complexing agent on the dissolution rate of BFS glass 


\section{Implications for current glass dissolution models and cement chemistry.}

Currently, two glass dissolution models are considered: (i) the leached layer model $[15,29,35-40]-$ a non-stoichiometric release of modifier cations leading to the formation of a chemically altered leached layer. Reaction rate is under diffusion control and may be compromised by the counter flow of ions from the bulk solution and from the bulk glass. (ii) the interfacial diffusion-reprecipitation model [41-45] - requires congruent dissolution occurring at one or more reaction fronts, each supported by a thin fluid film in contact with the dissolving phase (pristine glass or subsequent precipitate) under interface reaction controlled kinetics.

In the present study, $\mathrm{Ca}$ and $\mathrm{Al}$ enrichment at the surface of the glass, coupled with readsorption of $\mathrm{Ca}$ indicated from solution data, support a dissolution-reprecipitation mechanism, particularly because $\mathrm{Al}$ release is predominantly through network dissolution. This supports reaction on multiple fronts, potentially involving a number of different phases, each permeable to the aqueous solution and each locally conditioning its composition. Such short range conditioning is unlikely to be represented in the composition of the bulk solution and could account for the apparent contradiction between coupled dissolution- precipitation and the prediction of undersaturation with respect to known cement-relevant phases.

The influence of $\mathrm{Ca}$ on the reactivity of BFS glass in a cementitious system cannot be directly assessed from the current data because the synthetic glass used is not as compositionally complex as typical industrial slags. However, the effects observed may still be considered useful indicators of performance with some minor variations; $\mathrm{Mg}$ is very insoluble in slag cements, typically precipitating as hydrotalcite, $\left[\mathrm{Mg}_{0.75} \mathrm{Al}_{0.25}(\mathrm{OH})_{2}\right]\left(\mathrm{CO}_{3}\right)_{0.125}\left(\mathrm{H}_{2} \mathrm{O}\right)_{0.5}$; there will be some $\mathrm{Al}$ consumption due to the 
precipitation of hydrotalcite. Taking this into consideration, it is interesting to note that the effects of prehydration leading to surface accumulation and subsequent release of $\mathrm{Ca}$ into solution may also be expected from industrial ground granulated BFS, which is quenched and ground in the presence of water/moist air. The initial burst of activity long attributed to BFS hydration [46] and confirmed more recently by Kocaba, et al [9], would be consistent with an initial release of soluble $\mathrm{Ca}$. The effect of increased $\mathrm{Ca}$ concentrations in the pore water from cement hydration and/or the Ca deficient nearsurface of the glass (XPS data - Figure 6 and 7) may account for the dormant period which follows [9]. The timescales in real cement systems of course are much longer than in the present study as might be expected from the different w/s ratios used.

\section{Conclusions}

This early stage study of synthetic BFS-like glass activation has identified an initial rapid release of $\mathrm{Ca}$ in each of the activator systems studied. This release into solution can be correlated with a near surface accumulation of Ca as observed by ToFSIMS and associated with prehydration, similar to that reported by Hench [31]. Although the chemical environment is more complex in a cementitious mixture, this observation has relevance to the use of industrial ground granulated blastfurnace slag (GGBFS), which is quenched, and ground in the presence of water. The hydration kinetics of BFS are characterised by an initial burst of activity followed by a dormant period $[9,46]$. Such behaviour would be consistent with the early availability of $\mathrm{Ca}$, the reaction rate diminishing as the locally available Ca becomes exhausted. Although the timescales are highly compressed in the present study due to the high water/solid ratios used, the availability of $\mathrm{Ca}$ is important in controlling reactivity in the longer term as well. The deliberate addition of Ca reduces Si release from the glass and the 
sequestration of Ca by aqueous complexation enhances Si release. This particular observation translates to actual cement systems. Addition of the complexant, diethanolisopropanolamine (DEIPA) increased the degree of GGBFS hydration by around 10\% at 28 days [34].

\section{Acknowledgements}

The authors would like to thank Nanocem (www.nanocem.org), an industrialacademic partner in cement and concrete research, for their financial support, Thomas Matschei for solution modelling, and Jørgen Skibsted for assistance in various parts of

the study. The use of the ToF-SIMS and XPS facilities at Århus University (iNaNO) is much appreciated and particularly the support offered by Morten Foss and John Hansen.

\section{References}

[1] N. Tanaka, B. Stigson, Cement Technology Roadmap 2009: Carbon emissions reductions up to 2050, OECD Publishing, Paris, 2009.

[2] N. Tanaka, Energy Technology Perspectives: Scenarios \& Strategies To 2050, Int. Energy Agency Publ. (2010) 1-710. http://www.oecdilibrary.org.ezproxy.library.uq.edu.au/energy/energy-technology-perspectives2010_energy_tech-2010-en.

[3] C. Li, H. Sun, L. Li, A review: The comparison between alkali-activated slag (Si+Ca) and metakaolin (Si+Al) cements, Cem. Concr. Res. 40 (2010) 13411349. doi:10.1016/j.cemconres.2010.03.020.

[4] V.S. Dubovoy, S.H. Gebler, P. Klieger, D.A. Whiting, Effects of Ground Granulated Blast-Furnace Slags on Some Properties of Pastes, Mortars, and Concretes, ASTM Spec. Tech. Publ. STP897 (1986) 29-48. 
http://www.astm.org/DIGITAL_LIBRARY/STP/PAGES/STP36390S.htm.

[5] S.C. Pal, A. Mukherjee, S.R. Pathak, Investigation of hydraulic activity of ground granulated blast furnace slag in concrete, Cem. Concr. Res. 33 (2003) 14811486. doi:10.1016/S0008-8846(03)00062-0.

[6] H.F.W. Taylor, Cement Chemistry, 2nd ed., Thomas Telford Publishing, London, 1997.

[7] R. Snellings, G. Mertens, J. Elsen, Supplementary Cementitious Materials, Rev. Mineral. Geochemistry. 74 (2012) 211-278. doi:10.2138/rmg.2012.74.6.

[8] B. Lothenbach, K. Scrivener, R.D. Hooton, Supplementary cementitious materials, Cem. Concr. Res. 41 (2011) 1244-1256.

doi:10.1016/j.cemconres.2010.12.001.

[9] V. Kocaba, E. Gallucci, K.L. Scrivener, Methods for determination of degree of reaction of slag in blended cement pastes, Cem. Concr. Res. 42 (2012) 511-525. doi:10.1016/j.cemconres.2011.11.010.

[10] E. Berodier, K. Scrivener, Understanding the Filler Effect on the Nucleation and Growth of C-S-H, J. Am. Ceram. Soc. 10 (2014) 1-10. doi:10.1111/jace.13177.

[11] A. Novatski, A. Steimacher, A.N. Medina, A.C. Bento, M.L. Baesso, L.H.C. Andrade, et al., Relations among nonbridging oxygen, optical properties, optical basicity, and color center formation in $\mathrm{CaO}-\mathrm{MgO}$ aluminosilicate glasses, $\mathrm{J}$. Appl. Phys. 104 (2008). doi:10.1063/1.3010306.

[12] J.E. Shelby, Introduction to glass science and technology, Second Edi, The Royal Society of Chemistry, Cambridge, 2005.

[13] M. Moesgaard, D. Herfort, Y. Yue, Calcium aluminosilicate glasses as supplementary cementitious materials, Glas. Sci. Technol. 51 (2010) 183-190.

[14] D.R. Neuville, L. Cormier, V. Montouillout, D. Massiot, Local Al site 
distribution in aluminosilicate glasses by 27Al MQMAS NMR, J. Non. Cryst. Solids. 353 (2007) 180-184. doi:10.1016/j.jnoncrysol.2006.09.035.

[15] J. Hamilton, Dissolution of nepheline, jadeite and albite glasses: toward better models for aluminosilicate dissolution, Geochim. Cosmochim. Acta. 65 (2001) 3683-3702. doi:10.1016/S0016-7037(01)00724-4.

[16] E.M. Gartner, D.E. Macphee, A physico-chemical basis for novel cementitious binders, Cem. Concr. Res. 41 (2011) 736-749. doi:10.1016/j.cemconres.2011.03.006.

[17] S.L. Brantley, J.D. Kubicki, A.F. White, Kinetics of Water-Rock Interaction, Springer Science \& Business Media, New York, 2008.

[18] R.D. Shannon, Revised effective ionic radii and systematic studies of interatomic distances in halides and chalcogenides, Acta Crystallogr. Sect. A. 32 (1976) 751767. doi:10.1107/S0567739476001551.

[19] J. Depasse, a. Watillon, The stability of amorphous colloidal silica, J. Colloid Interface Sci. 33 (1970) 430-438. doi:10.1016/0021-9797(70)90235-3.

[20] H. Xu, J.S.J. Van Deventer, The geopolymerisation of alumino-silicate minerals, Int. J. Miner. Process. 59 (2000) 247-266. doi:10.1016/S0301-7516(99)00074-5.

[21] R. Hellmann, The albite-water system : Part II . The time-evolution of the stoichiometry of dissolution as a function of $\mathrm{pH}$ at 100,200 , and $300^{\circ} \mathrm{C}$, Geochim. Cosmochim. Acta. 59 (1995) 1669-1697.

[22] S. Mercado-Depierre, F. Angeli, F. Frizon, S. Gin, Antagonist effects of calcium on borosilicate glass alteration, J. Nucl. Mater. 441 (2013) 402-410. doi:10.1016/j.jnucmat.2013.06.023.

[23] L. Dohmen, C. Lenting, R.O.C. Fonseca, T. Nagel, A. Heuser, T. Geisler, et al., Pattern formation in silicate glass corrosion zones, Int. J. Appl. Glas. Sci. 4 
(2013) 357-370. doi:10.1111/ijag.12046.

[24] T. Chave, P. Frugier, S. Gin, a. Ayral, Glass-water interphase reactivity with calcium rich solutions, Geochim. Cosmochim. Acta. 75 (2011) 4125-4139. doi:10.1016/j.gca.2011.05.005.

[25] L.S. Dent Glasser, N. Kataoka, On the role of calcium in the alkali-aggregate reaction, Cem. Concr. Res. 12 (1982) 321-331.

[26] D.D. Perrin, Dissociation contants of inorganic acids and bases in aqueous solution, Pure Appl. Chem. 20 (1969) 133-236. doi:10.1351/pac196920020133.

[27] S. Tanuma, C.J. Powell, D.R. Penn, Calculations of electron inelestic mean free paths. IX. Data for 41 elemental solids over the $50 \mathrm{eV}$ to $30 \mathrm{keV}$ range, Surf. Interface Anal. 43 (2011) 689-713. doi:10.1016/j.nimb.2011.09.016.

[28] J.F. Watts, J. Wolstenholme, An Introduction to surface analysis by XPS and AES, John Wiley \& Sons, Inc., Chichester, 2003.

[29] P. Frugier, S. Gin, Y. Minet, T. Chave, B. Bonin, N. Godon, et al., SON68 nuclear glass dissolution kinetics: Current state of knowledge and basis of the new GRAAL model, J. Nucl. Mater. 380 (2008) 8-21. doi:10.1016/j.jnucmat.2008.06.044.

[30] R. Snellings, Surface Chemistry of Calcium Aluminosilicate Glasses, J. Am. Ceram. Soc. 98 (2015) 303-314. doi:10.1111/jace.13263.

[31] L.L. Hench, D.E. Clark, Physical chemistry of glass surfaces, J. Non. Cryst. Solids. 28 (1978) 83-105.

[32] K.C. Newlands, D.E. Macphee, The early stage dissolution characteristics of aluminosilicate glasses and their implications for SCM reactivity in cement systems, Weimar, 2015.

[33] C.A. Utton, R.J. Hand, N.C. Hyatt, S.W. Swanton, S.J. Williams, Formation of 
alteration products during dissolution of vitrified ILW in a high-pH calcium-rich solution, J. Nucl. Mater. 442 (2013) 33-45. doi:10.1016/j.jnucmat.2013.08.026.

[34] K. Riding, D.A. Silva, K. Scrivener, Early age strength enhancement of blended cement systems by $\mathrm{CaCl} 2$ and diethanol-isopropanolamine, Cem. Concr. Res. 40 (2010) 935-946. doi:10.1016/j.cemconres.2010.01.008.

[35] P. Van Iseghem, M. Aertsens, S. Gin, D. Deneele, B. Grambow, P. McGrail, et al., A Critical Evaluation of the Dissolution Mechanisms of High-level Waste Glasses in Conditions of Relevance for Geological Disposal (GLAMOR), 2007. doi:EUR 23097.

[36] E.H. Oelkers, General kinetic description of multioxide silicate mineral and glass dissolution, Geochim. Cosmochim. Acta. 65 (2001) 3703-3719. doi:10.1016/S0016-7037(01)00710-4.

[37] J.L. Crovisier, T. Advocat, J.L. Dussossoy, Nature and role of natural alteration gels formed on the surface of ancient volcanic glasses (Natural analogs of waste containment glasses), J. Nucl. Mater. 321 (2003) 91-109. doi:10.1016/S00223115(03)00206-X.

[38] G. Libourel, A. Verney-Carron, A. Morlok, S. Gin, J. Sterpenich, A. Michelin, et al., The use of natural and archeological analogues for understanding the longterm behavior of nuclear glasses, Comptes Rendus Geosci. 343 (2011) 237-245. doi:10.1016/j.crte.2010.12.004.

[39] B.C. Bunker, Molecular mechanisms for corrosion of silica and silicate glasses, J. Non. Cryst. Solids. 179 (1994) 300-308. doi:10.1016/0022-3093(94)90708-0.

[40] A. Tournie, P. Ricciardi, P. Colomban, Glass corrosion mechanisms: A multiscale analysis, Solid State Ionics. 179 (2008) 2142-2154. doi:10.1016/j.ssi.2008.07.019. 
[41] E. Ruiz-Agudo, C. V. Putnis, C. Rodriguez-Navarro, A. Putnis, Mechanism of leached layer formation during chemical weathering of silicate minerals, Geology. 40 (2012) 947-950. doi:10.1130/G33339.1.

[42] C. V. Putnis, K. Tsukamoto, Y. Nishimura, Direct observations of pseudomorphism: Compositional and textural evolution at a fluid-solid interface, Am. Mineral. 90 (2005) 1909-1912. doi:10.2138/am.2005.1990.

[43] T. Geisler, A. Janssen, D. Scheiter, T. Stephan, J. Berndt, A. Putnis, Aqueous corrosion of borosilicate glass under acidic conditions: A new corrosion mechanism, J. Non. Cryst. Solids. 356 (2010) 1458-1465. doi:10.1016/j.jnoncrysol.2010.04.033.

[44] R. Hellmann, J.M. Penisson, R.L. Hervig, J.H. Thomassin, M.F. Abrioux, An EFTEM/HRTEM high-resolution study of the near surface of labradorite feldspar altered at acid pH: Evidence for interfacial dissolution-reprecipitation, Phys. Chem. Miner. 30 (2003) 192-197. doi:10.1007/s00269-003-0308-4.

[45] A. Putnis, Mineral Replacement Reactions, Rev. Mineral. Geochemistry . 70 (2009) 87-124. doi:10.2138/rmg.2009.70.3.

[46] K. Luke, F.P. Glasser, Selective dissolution of hydrated blast furnace slag cements, Cem. Concr. Res. 17 (1987) 273-282. doi:10.1016/00088846(87)90110-4.

List of Figure Captions

Figure 1: Strength evolution in BFS-OPC blends (redrawn from [4])

Figure 2: Schematic representation of a glassy (no long range order) aluminosilicate network 
Figure 3. $\mathrm{CaO}-\mathrm{SiO} 2-\mathrm{Al} 2 \mathrm{O} 3$ ternary phase diagram (mol\%) showing the compositions of typical SCMs. The composition of the synthesised BFS glass is indicated.

Figure 4. Release of $\mathrm{Al}, \mathrm{Ca}$ and $\mathrm{Si}(\mathrm{mol} / \mathrm{cm} 2$ glass) vs. time (min) for BFS exposed to $\mathrm{H} 2 \mathrm{O}$ at $1 / \mathrm{s} 10,000$

Figure 5. Log of the normalised elemental fluxes $(\mathrm{mol} / \mathrm{cm} 2 / \mathrm{s})$ over time (min) for BFS in (a) $\mathrm{H} 2 \mathrm{O}$, (b) $0.1 \mathrm{M} \mathrm{NaOH}$, and (c) $0.1 \mathrm{M} \mathrm{KOH}$

Figure 6. Ion ratio plots for synthetic BFS glass exposed to $\mathrm{H}_{2} \mathrm{O}$.

Figure 7. Ion ratio plots for synthetic BFS glass exposed to $0.1 \mathrm{M} \mathrm{NaOH}$

Figure 8. Potential compositional profile in (a) $\mathrm{H}_{2} \mathrm{O}$-activated and (b) $0.1 \mathrm{M} \mathrm{NaOH}-$ activated BFS glass, based on ToF-SIMS and XPS data

Figure 9: Effect of Ca addition to the aqueous solution on; (a) Si and (b) Ca fluxes during dissolution in solutions with $0,0.5,1,2,8 \mathrm{mM} \mathrm{Ca}$ additions

Figure 10. Influence of a Ca-complexing agent on the dissolution rate of BFS glass 